\title{
Comparison of ultrasound-guided iliohypogastric/ilioinguinal nerve block and transversus abdominis plane block for analgesia after cesarean section: A retrospective propensity match study
}

\author{
YULU JIN $^{1}$, YONGLIANG LI ${ }^{2}$, SANRONG ZHU ${ }^{1}$, GUANGFENG ZHU ${ }^{3}$ and MIN YU ${ }^{4}$ \\ ${ }^{1}$ Department of Anesthesiology, Yueqing Third People's Hospital, Yueqing, Zhejiang 325604; \\ ${ }^{2}$ Department of Anesthesiology, Ruian People's Hospital, Ruian, Zhejiang 325200; ${ }^{3}$ Department of Anesthesiology, \\ Wenzhou Hospital of Integrated Traditional Chinese and Western Medicine, Wenzhou, Zhejiang 325003; \\ ${ }^{4}$ Department of Anesthesiology, Ruian Maternal and Child Health Hospital, Ruian, Zhejiang 325200, P.R. China
}

Received October 3, 2018; Accepted March 29, 2019

DOI: $10.3892 /$ etm.2019.7540

\begin{abstract}
Effective and adequate post-operative analgesia for cesarean section is in demand due to increasing rates of cesarean deliveries, and may help promote recovery, ambulation and breastfeeding. Local nerve block has been applied as post-operative analgesia for maternal patients receiving cesarean section; specifically, lateral abdominal transversus abdominis plane block (TAPB) and iliohypogastric/ilioinguinal nerve block (IHINB) under ultrasound guidance have been proven to be effective. The present study aimed to compare the analgesic effect of TAPB and IHINB in maternal females undergoing cesarean section. Propensity-matched females who received cesarean section $(n=124)$ were retrospectively enrolled and divided into the TAPB group $(n=62)$ and the IHINB group ( $n=62)$ according to their post-operative analgesia treatment. All of the patients have been given spinal-epidural anesthesia during the operation, while they received either TAPB or IHINB for post-operative analgesia. Demographic and clinical data were collected and compared, including time to first morphine request, cumulative morphine consumption, visual analogue scale (VAS) score and adverse events. Due to propensity matching, there was no significant difference between the two groups in their baseline characteristics (all $\mathrm{P}>0.05$ ). The log-rank test indicated no significant difference in the Kaplan-Meier curves for the time to first morphine request between the two groups $(\mathrm{P}=0.575)$. The VAS score and cumulative morphine consumption at 6 and $12 \mathrm{~h}$ was similar between the two groups (all $\mathrm{P}>0.05$ ). However, these two parameters were significantly lower in the IHINB
\end{abstract}

Correspondence to: Dr Min Yu, Department of Anesthesiology, Ruian Maternal and Child Health Hospital, 521 Wansong East Road, Ruian, Zhejiang 325200, P.R. China

E-mail: ruianyumin@qq.com

Key words: iliohypogastric/ilioinguinal nerve block, transversus abdominis plane block, analgesia, cesarean section group at 24 and $48 \mathrm{~h}(\mathrm{P}<0.001)$. Uni- and multivariate logistic regression analysis indicated that the method of block was not an independent influencing factor regarding postoperative pain relief $(\mathrm{P}=0.628)$. There was also no difference between the two groups in adverse events of analgesia (all $\mathrm{P}>0.05$ ). In conclusion, the present study demonstrated that TAPB and IHINB achieved a comparably satisfactory analgesic effect after cesarean section. However, the analgesic effect of IHINB was better than that of TAPB at the later stages.

\section{Introduction}

Cesarean section rates have been increasing worldwide, particularly in Asian countries, and accordingly, there has been demand for improved healthcare for maternal females undergoing cesarean section (1). Post-cesarean analgesia has an important role in the entire analgesia, not only improving the subjective pain, but also accelerating post-operative recovery and reducing the incidence of venous thrombosis (2). Multiple modes of analgesia are available for cesarean section, including epidural analgesia, peripheral nerve blocks, oral painkillers and intravenous morphine. Despite its high efficacy, epidural analgesia is usually terminated immediately after the surgery, and its residual effect gradually disappears within $24 \mathrm{~h}$ (3). Subsequent to termination of epidural anesthesia, other methods of analgesia must be selected, while intravenous morphine is less preferred due to its adverse effects (4).

With the application of ultrasound guidance, local nerve block has recently gained worldwide popularity. Transversus abdominis plane block (TAPB) is a regional analgesic technique applied in post-operative analgesia for lower abdominal surgeries. Numerous studies have demonstrated that TAPB reduces post-operative opioid consumption and opioid-associated side effects. Iliohypogastric/ilioinguinal block (IHINB) is another means of post-operative analgesia for lower abdominal surgeries (5). IHINB is also proven to be effective in reducing cumulative morphine consumption but not the side effects (6). Various studies have compared the analgesic effects of TAPB and IHINB in abdominal surgeries, including inguinal hernia repair (7-9). However, they are limited to a relatively small 
sample size and the results are inconsistent. Furthermore, previously provided evidence for comparing the analgesic effects and complications between TAPB and IHINB in cesarean section is limited. In the present study, by retrospectively collecting clinical data of propensity-matched maternal females undergoing cesarean section, the analgesic effects and complications of TAPB and IHINB were compared.

\section{Materials and methods}

Patients. The clinical data of 368 maternal females who underwent cesarean section at Yueqing Third People's Hospital (Yueqing, China) between June 2016 and June 2017 were retrospectively collected. The inclusion criteria were as follows: i) Cesarean section under epidural analgesia; ii) peripheral nerve block, including TAPB or IHINB; iii) age of 18-40 years; iv) ASA grade I or II according to the American Society of Anesthesiologists (ASA) classification (10); v) complete data of pain evaluation, morphine request and consumption. A total of 242 patients met the above criteria, and after the propensity score match, 124 patients were finally included in the study, who were divided into the TAPB group and the IHINB group according to their post-operative analgesic treatment modality. The study design is presented in the flow chart in Fig. 1.

Demographic characteristics and clinical data of the subjects were collected from the electronic database of the hospital for analysis, with written informed consent provided by the patients on admission for inclusion of their data in scientific studies. The present study was approved by the Medical Ethics Committee of Yueqing Third People's Hospital (Yueqing, China).

Anesthesia. All patients were given combined spinal-epidural anesthesia in the operating room, with monitoring of arterial blood pressure, electrocardiogram and peripheral pulse oximetry performed. The patients were placed in the left lateral decubitus position, and epidural anesthesia was given by a needle-through-needle technique at the L3/4 interspace. The first dose of intrathecal hyperbaric bupivacaine $(12 \mathrm{mg})$ and fentanyl $(10 \mu \mathrm{g})$ was injected, and an epidural catheter was then secured $4-5 \mathrm{~cm}$ into the epidural space. If hypesthesia to ice up to Th4 was not achieved, incremental doses of $5 \mathrm{ml}$ $2 \%$ lidocaine were administered into the epidural space. At the time of closing the peritoneum, $2 \mathrm{mg}$ morphine hydrochloride with $5 \mathrm{ml}$ saline was administered through the epidural catheter.

Post-operative analgesia. As previously described, TAPB or IHINB was performed after the surgery $(11,12)$. For TAPB, the skin was first prepared with an antiseptic solution. The convex 3.5-MHz ultrasound probe (Sonosite EDGE Portable Ultrasound System; SonoSite) was transversally placed on the anterior axillary line halfway between the costal margin and the iliac crest and then moved toward the navel until the three layers of muscles (external and internal oblique muscles and transversus abdominis muscle), the peritoneum and intraperitoneal structures were clearly visible. Under the guidance of ultrasound, the 22G 100-mm echo-lucent needle was chosen and then inserted posteriorly into the transversus abdominis fascial plane. A test injection of 1-2 $\mathrm{ml}$ glucose was given to

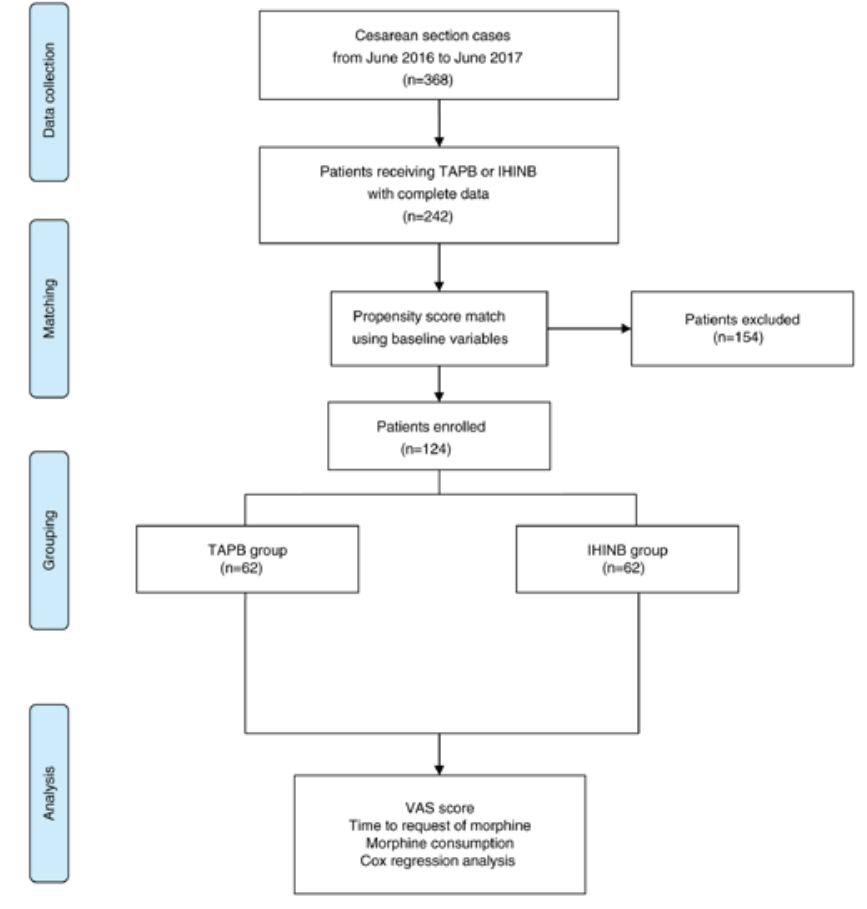

Figure 1. Flow chart presenting the design of the study. VAS, visual analog scale; TAPB, transversus abdominis plane block; IHINB, iliohypogastric/ilioinguinal nerve block.

confirm the correct position of the block needle in the transversus abdominis fascial plane. After the confirmation, $20 \mathrm{ml}$ $0.375 \%$ ropivacaine or $0.3 \%$ levobupivacaine (decided by the anesthesiologists according to their preference) was injected into the fascial plane on each side in 5-ml increments after aspiration.

For IHINB, the convex $3.5-\mathrm{MHz}$ ultrasound probe (Sonosite EDGE Portable Ultrasound System; SonoSite) was placed on the line between the anterior superior iliac spine and the umbilicus, where 3 layers of muscles (extra-abdominal oblique, intra-abdominal oblique and transverse abdominis) were visible on the inner side of the anterior superior iliac spine.

The inferior tibiofibular and iliac crest nerves were identified between the abdominal oblique muscle and the transverse abdominis muscle. Under the guidance of ultrasound, the $22 \mathrm{G}$ $100-\mathrm{mm}$ echo-lucent needle was selected and then inserted next to the iliohypogastric/ilioinguinal nerve. The dose and selection of local anesthetics were the same as those used for TAPB.

All patients were given a standardized patient-controlled intravenous analgesia (PCIA) regimen. The disposable PCIA device (Coopdech Syrinjector PCA set; Daiken Medical) contained $30 \mathrm{mg}$ morphine in $45 \mathrm{ml}$ saline. Patients were instructed on how to use the PCIA device, which was set with a bolus of $2 \mathrm{mg}$ morphine and a minimum interval of $30 \mathrm{~min}$. In addition, the first time of using PCIA was recorded in hospital documents. If the analgesic effect was not satisfactory, complementary use of intravenous morphine was applied.

Data collection. Demographics and clinical characteristics, including age, gender, body mass index, level of education and ASA grade were all collected from the electric database of the 
Table I. Demographical and clinical characteristics of all maternal females undergoing cesarean section prior to propensity match.

\begin{tabular}{|c|c|c|c|c|}
\hline Variables & TAPB group $(n=122)$ & IHINB group $(n=120)$ & $t / \chi^{2}$ & P-value \\
\hline \multicolumn{5}{|l|}{ Demographics } \\
\hline Age (years) & $28.0 \pm 4.2$ & $29.3 \pm 4.2$ & 2.497 & 0.013 \\
\hline Weight (kg) & $78.8 \pm 12.5$ & $80.8 \pm 12.7$ & 1.249 & 0.213 \\
\hline Height (cm) & $160.2 \pm 5.8$ & $160.5 \pm 5.7$ & 0.274 & 0.784 \\
\hline BMI $\left(\mathrm{kg} / \mathrm{m}^{2}\right)$ & $30.8 \pm 5.1$ & $31.5 \pm 5.5$ & 1.139 & 0.256 \\
\hline Education & & & 11.564 & 0.009 \\
\hline Illiteracy & $28(23.0)$ & $37(21.7)$ & & \\
\hline Elementary school & $36(29.5)$ & $47(13.3)$ & & \\
\hline High school & $33(27.0)$ & $36(31.7)$ & & \\
\hline College or higher & $25(20.5)$ & $22(33.3)$ & & \\
\hline ASA grade & & & 0.081 & 0.775 \\
\hline $\mathrm{I}$ & $71(58.2)$ & $72(60.0)$ & & \\
\hline II & $51(41.8)$ & $48(40.0)$ & & \\
\hline Local anesthetics & & & 3.096 & 0.078 \\
\hline Ropivacaine & $91(74.6)$ & $77(64.2)$ & & \\
\hline Levobupivacaine & $31(25.4)$ & $43(35.8)$ & & \\
\hline Gestational week & $38.5 \pm 1.8$ & $38.6 \pm 1.6$ & 0.605 & 0.546 \\
\hline
\end{tabular}

Values are expressed as the mean \pm standard deviation or n (\%). BMI, body mass index; ASA, American Society of Anesthesiologists; TAPB, transversus abdominis plane block; IHINB, iliohypogastric/ilioinguinal nerve block.

hospital. The time to first request of morphine, visual analog scale (VAS) score and dose of morphine used after the surgery were also recorded. The VAS score and dose of morphine were evaluated at different time-points after surgery. The VAS score was determined using a $10-\mathrm{cm}$ scale to represent the extent of pain, with 0 points resembling no pain and 10 points indicating the most severe pain imaginable.

Statistical analysis. In the present study, SPSS version 19.0 (IBM Corp., Armonk, NY, USA) was used for statistical analysis. Continuous variables meeting the criteria for normal distribution were expressed as the mean \pm standard deviation and categorical variables were presented as proportions. The propensity score was calculated using multivariate logistic regression, taking into account demographical and clinical variables. Patients with the highest similarity in propensity scores were matched using the 'greedy match' method. Following the propensity score matching, a normal distribution test using the Kolmogorov-Smirnov method was adopted for all variables. Continuous data meeting the normal distribution criteria were analyzed using Student's t-test, while those not meeting those criteria were assessed with a non-parametric Mann-Whitney U-test. The $\chi^{2}$ test was adopted for categorical variables in the analysis.

As for the Kaplan-Meier analysis, the Cox proportional hazard model was adopted as the regression method to compare the relative hazard ratio of morphine requests for various covariates, while Kaplan-Meier curves and log-rank tests were used for comparing the time to first request of morphine between the groups. $\mathrm{P}<0.05$ was considered to indicate statistical significance.

\section{Results}

Demographic and clinical characteristics. As presented in Table I, there were significant differences between the TAPB group and the IHINB group in age $(\mathrm{P}=0.013)$ and education $(\mathrm{P}=0.009)$ prior to the propensity match. However, these differences were eliminated by screening the patients by means of propensity score match. Table II indicates that after the match, there was no difference between the two groups in demographics and clinical characteristics (all $\mathrm{P}>0.05$ ). Furthermore, the local anesthetics used in the different groups were similar $(\mathrm{P}=0.206)$.

Time to first morphine request. The Kaplan-Meier curves depicting the time to first morphine request in the two groups are provided in Fig. 2. Although the mean value in the TAPB group was lower than that in the IHINB group $(1,327 \pm 960$ vs. $1,504 \pm 834 \mathrm{~min})$, the log-rank test demonstrated that there was no significant difference $(\mathrm{P}=0.575)$.

VAS score and cumulative morphine consumption. The VAS score and cumulative morphine consumption were compared between the two groups. As for the VAS score, there was no significant difference between the two groups in the first $12 \mathrm{~h}$ (all P>0.05). However, the VAS score of the IHINB group was significantly lower than that of the TAPB group at 24 and $48 \mathrm{~h}$ after the surgery $(\mathrm{P}<0.001$ for each; Fig. 3). Similar to the VAS score, the total cumulative morphine consumption in the two groups was comparable at $12 \mathrm{~h}$, while it was significantly lower for the IHINB group at 24 and $48 \mathrm{~h}$ after the surgery $(\mathrm{P}<0.05$ and $\mathrm{P}<0.001$ respectively; Fig. 4). 
Table II. Demographical and clinical characteristics of propensity scoring-matched maternal females undergoing cesarean section.

\begin{tabular}{|c|c|c|c|c|}
\hline Variables & TAPB group $(n=62)$ & IHINB group $(n=62)$ & $\mathrm{t} / \chi^{2}$ & P-value \\
\hline \multicolumn{5}{|l|}{ Demographics } \\
\hline Age (years) & $28.2 \pm 3.3$ & $28.6 \pm 3.8$ & 0.586 & 0.559 \\
\hline Weight (kg) & $81.7 \pm 12.4$ & $80.2 \pm 10.7$ & 0.698 & 0.487 \\
\hline Height (m) & $160.0 \pm 5.8$ & $161.0 \pm 5.6$ & 1.021 & 0.309 \\
\hline $\mathrm{BMI}\left(\mathrm{kg} / \mathrm{m}^{2}\right)$ & $32.0 \pm 5.4$ & $31.0 \pm 4.6$ & 1.083 & 0.281 \\
\hline Education & & & 1.382 & 0.710 \\
\hline Illiteracy & $19(30.6)$ & $16(25.8)$ & & \\
\hline Elementary school & $10(16.1)$ & $9(14.5)$ & & \\
\hline High school & $16(25.8)$ & $22(35.5)$ & & \\
\hline College or higher & $17(27.4)$ & $15(24.2)$ & & \\
\hline ASA grade & & & 0.132 & 0.716 \\
\hline I & $37(59.7)$ & $35(56.5)$ & & \\
\hline II & $25(40.3)$ & $27(43.5)$ & & \\
\hline Local anesthetics & & & 1.601 & 0.206 \\
\hline Ropivacaine & $31(50.0)$ & $38(61.3)$ & & \\
\hline Levobupivacaine & $31(50.0)$ & $24(38.7)$ & & \\
\hline Gestational week & $38.5 \pm 1.8$ & $38.5 \pm 1.6$ & 0.159 & 0.874 \\
\hline
\end{tabular}

Values are expressed as the mean \pm standard deviation or n (\%). BMI, body mass index; ASA, American Society of Anesthesiologists; TAPB, transversus abdominis plane block; IHINB, iliohypogastric/ilioinguinal nerve block.

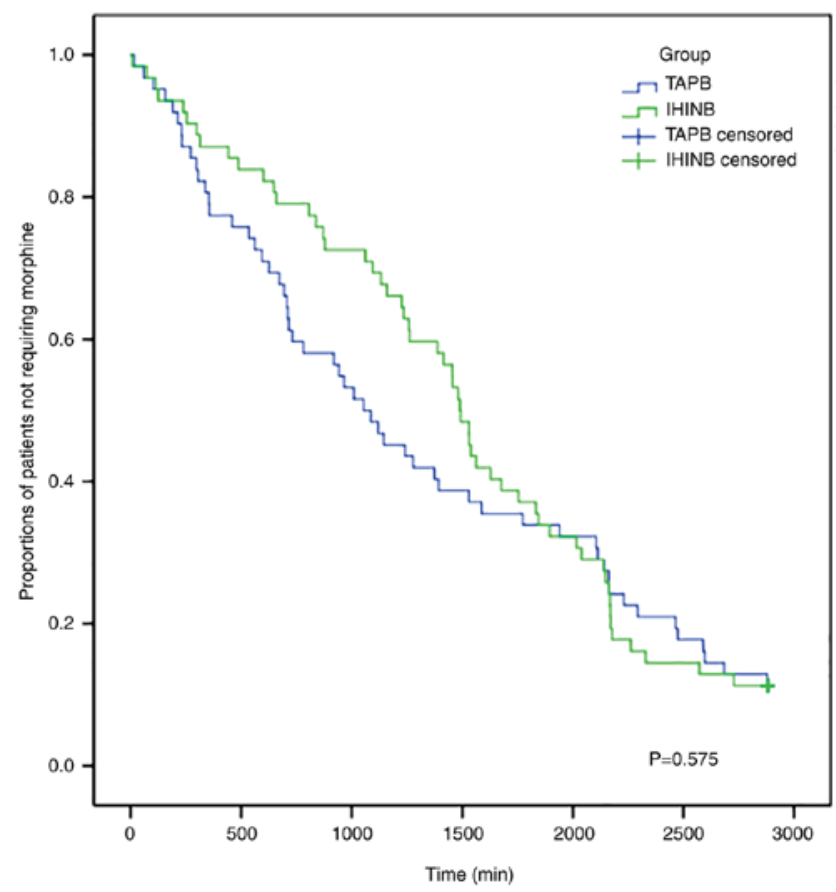

Figure 2. Kaplan-Meier curves illustrating the time to first morphine request in the TAPB group and IHINB group. TAPB, transversus abdominis plane block; IHINB, iliohypogastric/ilioinguinal nerve block.

Risk factors for post-operative analgesia. A Cox regression analysis was performed to determine the major risk factors for the analgesic effect in cesarean section patients, (Table III). Uni- and multivariate analysis demonstrated that the patient age and education level were independent risk factors for the time

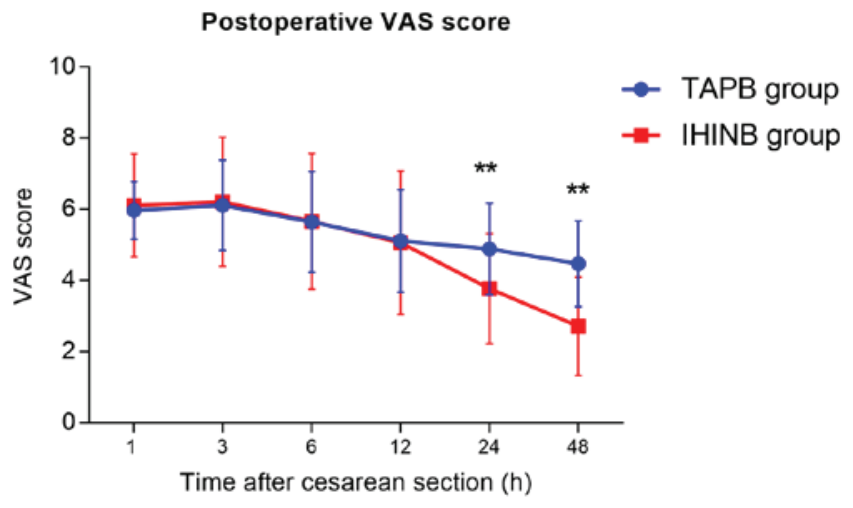

Figure 3. Post-operative VAS score in the TAPB group and IHINB group. ${ }^{* *} \mathrm{P}<0.001$. TAPB, transversus abdominis plane block; IHINB, iliohypogastric/ilioinguinal nerve block; VAS, visual analog scale.

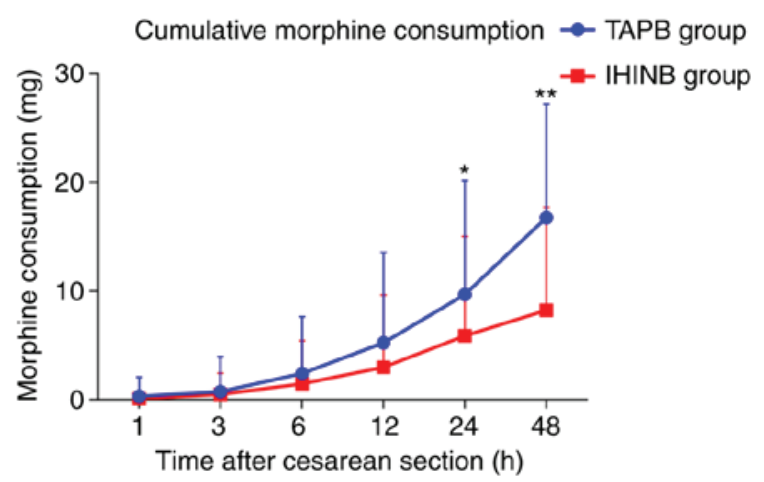

Figure 4. Post-operative cumulative morphine consumption in the TAPB group and IHINB group. ${ }^{*} \mathrm{P}<0.05,{ }^{* *} \mathrm{P}<0.001$. TAPB, transversus abdominis plane block; IHINB, iliohypogastric/ilioinguinal nerve block. 
Table III. Cox regression analysis of the association of covariates with the time to first morphine request.

\begin{tabular}{|c|c|c|c|c|c|c|}
\hline \multirow[b]{2}{*}{ Covariates } & \multicolumn{3}{|c|}{ Univariate } & \multicolumn{3}{|c|}{ Multivariate } \\
\hline & HR & $95 \% \mathrm{CI}$ & P-value & HR & $95 \%$ CI & P-value \\
\hline Age (years) & 0.914 & $0.866-0.965$ & 0.001 & 0.927 & $0.876-0.980$ & 0.008 \\
\hline Weight $(\mathrm{kg})$ & 1.007 & $0.990-1.023$ & 0.429 & NA & NA & NA \\
\hline Height (m) & 1.009 & $0.976-1.043$ & 0.591 & NA & NA & NA \\
\hline BMI $\left(\mathrm{kg} / \mathrm{m}^{2}\right)$ & 1.009 & $0.972-1.047$ & 0.654 & NA & NA & $\mathrm{NA}$ \\
\hline \multicolumn{7}{|l|}{ Educationa } \\
\hline Illiteracy & NA & NA & NA & NA & NA & NA \\
\hline Elementary school & 2.973 & $1.578-5.600$ & 0.001 & 3.078 & $1.628-5.819$ & 0.001 \\
\hline High school & 2.760 & $1.630-4.675$ & $<0.001$ & 2.662 & $1.569-4.516$ & $<0.001$ \\
\hline College or higher & 3.132 & $1.799-5.454$ & $<0.001$ & 2.666 & $1.506-4.719$ & 0.001 \\
\hline ASA grade & 1.119 & $0.767-1.631$ & 0.561 & NA & NA & NA \\
\hline Local anesthetics (levobupivacaine vs. ropivacaine) & 0.862 & $0.591-1.257$ & 0.441 & NA & NA & NA \\
\hline Gestational week & 1.099 & $0.982-1.230$ & 0.102 & 1.037 & $0.924-1.163$ & 0.539 \\
\hline Post-operative analgesic (TAPB vs. IHINB) & 0.898 & $0.617-1.308$ & 0.575 & 0.910 & $0.622-1.332$ & 0.628 \\
\hline
\end{tabular}

BMI, body mass index; ASA, American Society of Anesthesiologists; TAPB, transversus abdominis plane block; IHINB, iliohypogastric/ilioinguinal nerve block; NA, not acquired. aEach education level compared with Illiteracy.

Table IV. Adverse events of analgesia in the two groups.

\begin{tabular}{lccrr}
\hline Complication & TAPB group $(\mathrm{n}=62)$ & IHINB group (n=62) & $\chi^{2}$ & P-value \\
\hline Hypotension & $7(11.3)$ & $10(16.1)$ & 0.614 & 0.603 \\
Bradycardia & $3(4.8)$ & $4(6.5)$ & 0.151 & $>0.999$ \\
Arrhythmia & $0(0.0)$ & $2(3.2)$ & 2.033 & 0.496 \\
Nausea & $12(19.4)$ & $7(11.3)$ & 1.554 & 0.319 \\
Vomiting & $7(11.3)$ & $8(12.9)$ & 0.076 & 1.000 \\
Urinary retention & $10(16.1)$ & $18(29.0)$ & 2.952 & 0.132 \\
Pruritus & $32(51.6)$ & $35(56.5)$ & 0.292 & 0.589 \\
Total & $47(75.8)$ & $48(77.4)$ & 0.045 & 0.832 \\
\hline
\end{tabular}

Values are expressed as n (\%). TAPB, transversus abdominis plane block; IHINB, iliohypogastric/ilioinguinal nerve block.

to first morphine request. However, the mode of post-operative analgesia (TAPB or IHINB) was not a significant risk factor $(\mathrm{P}=0.628)$. In addition, the type of local anesthetic was not an independent risk factor $(\mathrm{P}=0.441)$.

Side effects of post-operative analgesia. Table IV presents the prevalence of common adverse events of post-operative analgesia in the groups, including hypotension, bradycardia, arrhythmia, nausea, vomiting, pruritus and urinary retention. Statistical analysis indicated that no significant difference in any of the adverse events was present between the two groups (all $\mathrm{P}>0.05$ ).

\section{Discussion}

The present study retrospectively compared the clinical data of cesarean section patients who received TAPB or IHINB for post-operative analgesia. By using propensity score matching, the differences in demographics and baseline characteristics were eliminated, which made the results more convincing. The results indicated that the analgesic effect of TAPB and IHINB was similar, but IHINB had a stronger effect a $24 \mathrm{~h}$ after the surgery.

The application of ultrasound in local nerve block may significantly increase the accuracy of punctuation and decrease the incidence of adverse events, which promotes the use of nerve block in post-operative analgesia (13). In the present cohort, nerve block was successfully performed in all cases without any complications. As for the selection of local anesthetics, a randomized controlled study indicated that levobupivacaine was more potent than ropivacaine in peripheral nerve block to a certain extent (14). Either levobupivacaine or ropivacaine was used in the present study, which depended on the anesthesiologists' judgement. However, the proportions 
of patients using either of the two different local anesthetics were similar between the two groups, while the Cox regression analysis also indicated that the type of local anesthetic had no significant effect on the time to first request of morphine. A number of studies have demonstrated that combination of local nerve block in postoperative analgesia may significantly enhance the analgesic effect and reduce the usage of morphine for patients undergoing cesarean section $(5,11,15,16)$.

TAPB, which was first described by McDonnell and Laffey (17), blocks sensory nerves that supply the anterior abdominal wall by deposition of local anesthetics. When the needle is advanced across the neurofascial planes of the anterior abdominal wall, the TAPB significantly enhances the analgesic effect (18). However, Lee et al (19) indicated that the major targets of TAPB were T10-T12 nerves, while the L1 nerve was merely blocked in half of the cases. The major reasons for this unsatisfactory effect of TAPB on the L1 nerve may be attributed to its varied anatomical pathways (20). However, the sensory nerve dominating the pain stimulus of uterine incision for cesarean section is the segment of the T12 and L1 nerves, while the iliohypogastric/ilioinguinal nerve are major branches of the L1 nerve. Furthermore, TAP block is a field block while IHINB is a truncal block. Hence, it was hypothesized that IHINB had a better effect than TAPB. A prospective randomized controlled open-label study led by Okur et al (21) compared the postoperative analgesic effect of TAPB and IHINB in patients undergoing inguinal herniorrhaphy with spinal anesthesia, revealing that TAPB and IHINB have a better effect than the controls using morphine only, and the time to first request of morphine in patients with the IHINB was shorter than the other two groups (21). However, TAPB and IHINB as post-operative analgesia for cesarean section has been rarely reported (5). Similar results from the study by Okur et al (21) were obtained in the present study, with the analgesic effect of TAPB and IHINB being comparable after the first $12 \mathrm{~h}$. However, better analgesia was achieved in the IHINB group than that in the TAPB group after $24 \mathrm{~h}$, with a lower VAS score and morphine consumption. Of note, multiple modes of analgesia in addition to local nerve block must be given for patients undergoing cesarean section, since the pain is a combination of somatic pain and visceral pain (22). TAPB and IHINB only block the somatic pain, while the visceral pain should be relieved by other methods, including intravenous morphine by PCIA. The common associated adverse events of TAPB and IHINB were also compared in the present study, with no statistical difference observed between the two groups, which was in accordance with other studies $(9,23,24)$.

Several limitations of the present study must be noted. First, although a propensity score match was performed, the present retrospective study inevitably had shortcomings of non-randomization, incomplete clinical data and retrospective analysis, which limited the power of evidence. Furthermore, the sample size may have been insufficient to determine the difference of major outcomes and potential adverse events, and future studies with larger cohorts should be performed for further elucidation. Finally, the dosage data of local anesthetics were missing, and it was therefore impossible to compare them between the two groups, while it was previously demonstrated that IHINB required less anesthetics than TAPB (25).
In summary, TAPB and IHINB were comparable at providing satisfactory post-operative analgesia and reducing morphine consumption for maternal females after cesarean section; however, IHINB had a better effect at $24 \mathrm{~h}$ after the surgery.

\section{Acknowledgements}

Not applicable.

\section{Funding}

No funding was received.

\section{Availability of data and materials}

The datasets used and/or analyzed are available from the corresponding author on reasonable request.

\section{Authors' contributions}

YJ and MY designed and led the current study. YL, SZ and GZ collected and analyzed the general patient data. YJ and YL wrote the manuscript and MY revised it. All authors read and approved the final manuscript.

\section{Ethics approval and consent to participate}

This study was approved by the Medical Ethics Committee of Yueqing Third People's Hospital (Yueqing, China). The patients provided written informed consent regarding the use of their data.

\section{Patient consent for publication}

Not applicable.

\section{Competing interests}

The authors declare that they have no competing interests.

\section{References}

1. Lumbiganon P, Laopaiboon M, Gülmezoglu AM, Souza JP, Taneepanichskul S, Ruyan P, Attygalle DE, Shrestha N, Mori R, Nguyen DH, et al; World Health Organization Global Survey on Maternal and Perinatal Health Research Group: Method of delivery and pregnancy outcomes in Asia: The WHO global survey on maternal and perinatal health 2007-08. Lancet 375: 490-499, 2010.

2. Wagner M: Epidural analgesia and risk of caesarean section. Lancet 353: 594, 1999.

3. Hawkins JL: Epidural analgesia for labor and delivery. N Engl J Med 362: 1503-1510, 2010.

4. El Aish KA, Tafish R and Zourob H: Morphine versus fentanyl for spinal post-caesarean analgesia: A randomised controlled trial. Lancet 391 (Suppl 2): S20, 2018.

5. Gucev G, Yasui GM, Chang TY and Lee J: Bilateral ultrasound-guided continuous ilioinguinal-iliohypogastric block for pain relief after cesarean delivery. Anesth Analg 106: 1220-1222, table of contents, 2008.

6. Bell EA, Jones BP, Olufolabi AJ, Dexter F, Phillips-Bute B, Greengrass RA, Penning DH and Reynolds JD; Duke Women's Anesthesia Research Group: Iliohypogastric-ilioinguinal peripheral nerve block for post-Cesarean delivery analgesia decreases morphine use but not opioid-related side effects. Can J Anaesth 49: 694-700, 2002 (In English, French). 
7. Kamal K, Jain P, Bansal T and Ahlawat G: A comparative study to evaluate ultrasound-guided transversus abdominis plane block versus ilioinguinal iliohypogastric nerve block for post-operative analgesia in adult patients undergoing inguinal hernia repair Indian J Anaesth 62: 292-297, 2018.

8. Bhatia N, Sen IM, Mandal B and Batra A: Postoperative analgesic efficacy of ultrasound-guided ilioinguinal-iliohypogastric nerve block compared with medial transverse abdominis plane block in inguinal hernia repair: A prospective, randomised trial. Anaesth Crit Care Pain Med 38: 41-45, 2019.

9. Sujatha C,Zachariah M,Ranjan RV, George SK, Ramachandran TR and Pillai AR: Transversus Abdominis Plane Block versus Ilioinguinal/Iliohypogastric Nerve Block with Wound Infiltration for Postoperative Analgesia in Inguinal Hernia Surgery: A Randomized Clinical Trial. Anesth Essays Res 11: 976-980, 2017.

10. Kiefer N, Krahe S, Gembruch U and Weber S: Ultrasound anatomy of the transversus abdominis plane region in pregnant women before and after cesarean delivery. BMC Anesthesiol 16 : $126,2016$.

11. Tan TT, Teoh WH, Woo DC, Ocampo CE, Shah MK and Sia AT: A randomised trial of the analgesic efficacy of ultrasound-guided transversus abdominis plane block after caesarean delivery under general anaesthesia. Eur J Anaesthesiol 29: 88-94, 2012.

12. Sakalli M, Ceyhan A, Uysal HY, Yazici I and Başar H: The efficacy of ilioinguinal and iliohypogastric nerve block for postoperative pain after caesarean section. J Res Med Sci 15: 6-13, 2010.

13. Kagwa S, Hoeft MA, Firth PG, Ttendo S and Modest VE: Ultrasound guided transversus abdominis plane versus sham blocks after caesarean section in an Ugandan village hospital: A prospective, randomised, double-blinded, single-centre study. Lancet 385 (Suppl 2): S36, 2015.

14. Li A, Wei Z, Liu Y, Shi J, Ding H, Tang H, Zheng P, Gao Y and Feng S: Ropivacaine versus levobupivacaine in peripheral nerve block: A PRISMA-compliant meta-analysis of randomized controlled trials. Medicine (Baltimore) 96: e6551, 2017.

15. Champaneria R, Shah L, Wilson MJ and Daniels JP: Clinical effectiveness of transversus abdominis plane (TAP) blocks for pain relief after caesarean section: A meta-analysis. Int J Obstet Anesth 28: 45-60, 2016.

16. Fusco P, Cofini V, Petrucci E, Scimia P, Pozone T, Paladini G, Carta G, Necozione S, Borghi B and Marinangeli F: Transversus Abdominis Plane Block in the Management of Acute Postoperative Pain Syndrome after Caesarean Section: A Randomized Controlled Clinical Trial. Pain Physician 19: 583-591, 2016
17. McDonnell JG and Laffey JG: Transversus abdominis plane block. Anesth Analg 105: 883, 2007.

18. Onishi Y, Kato R, Okutomi T, Tabata K, Amano K and Unno N: Transversus abdominis plane block provides postoperative analgesic effects after cesarean section: Additional analgesia to epidural morphine alone. J Obstet Gynaecol Res 39: 1397-1405, 2013.

19. Lee TH, Barrington MJ, Tran TM, Wong D and Hebbard PD: Comparison of extent of sensory block following posterior and subcostal approaches to ultrasound-guided transversus abdominis plane block. Anaesth Intensive Care 38: 452-460, 2010.

20. Tran TM, Ivanusic JJ, Hebbard P and Barrington MJ: Determination of spread of injectate after ultrasound-guided transversus abdominis plane block: A cadaveric study. Br J Anaesth 102: 123-127, 2009.

21. Okur O, Tekgul ZT and Erkan N: Comparison of efficacy of transversus abdominis plane block and iliohypogastric/ilioinguinal nerve block for postoperative pain management in patients undergoing inguinal herniorrhaphy with spinal anesthesia: A prospective randomized controlled open-label study. J Anesth 31: 678-685, 2017.

22. Zwissler B: Regional anesthesia and analgesia for labor and delivery. N Engl J Med 348: 1818-1820, author reply 1818-1820, 2003.

23. Mei W, Jin C, Feng L, Zhang Y, Luo A, Zhang C and Tian Y: Bilateral ultrasound-guided transversus abdominis plane block combined with ilioinguinal-iliohypogastric nerve block for cesarean delivery anesthesia. Anesth Analg 113: 134-137, 2011.

24. Coffman JC, Fiorini K, Ristev G, Beeston W and Small RH: Transversus abdominis plane and ilioinguinal/iliohypogastric blocks for cesarean delivery in a patient with type II spinal muscular atrophy. Int J Obstet Anesth 25: 79-81, 2016.

25. Eichenberger U, Greher M, Kirchmair L, Curatolo M and Moriggl B: Ultrasound-guided blocks of the ilioinguinal and iliohypogastric nerve: Accuracy of a selective new technique confirmed by anatomical dissection. Br J Anaesth 97: 238-243, 2006

This work is licensed under a Creative Commons Attribution-NonCommercial-NoDerivatives 4.0 International (CC BY-NC-ND 4.0) License. 